\title{
BMJ Open Internal consistency and reliability of the Swiss-French translation of the venous leg ulcer self efficacy tool (VeLUSET)
}

\author{
Sebastian Probst (D) , ${ }^{1}$ Mathieu Turcotte, ${ }^{2}$ Monika Buehrer Skinner ${ }^{3}$
}

To cite: Probst S, Turcotte M, Buehrer Skinner M. Internal consistency and reliability of the Swiss-French translation of the venous leg ulcer self efficacy tool (VeLUSET). BMJ Open 2019;9:e031529. doi:10.1136/ bmjopen-2019-031529

- Prepublication history for this paper is available online. To view these files, please visit the journal online (http://dx.doi. org/10.1136/bmjopen-2019031529).

Received 09 May 2019 Revised 07 November 2019 Accepted 11 November 2019

A) Check for updates

(c) Author(s) (or their employer(s)) 2019. Re-use permitted under CC BY-NC. No commercial re-use. See rights and permissions. Published by BMJ.

${ }^{1}$ Geneva School of Health Sciences, HES-SO Genève, Genève, Switzerland

${ }^{2}$ La Source, HES-SO, Lausanne, Switzerland

${ }^{3}$ Epidemiology, Biostatistics and Prevention Institute, University of Zurich, Zurich, Switzerland

Correspondence to

Professor Sebastian Probst; sebastian.probst@hesge.ch

\section{ABSTRACT}

Objective This study was conducted to assess the psychometric properties of the translated and adapted Venous Leg Ulcer Self Efficacy Tool (VeLUSET) in the new cultural context.

Design Validation study

Setting Three outpatient clinics in Western Switzerland. Participants 32 consecutive persons with venous leg ulcers (VLU).

Main outcome measures To determine the internal consistency and reliability of the VeLUSET for use in a Swiss-French speaking venous leg ulcer population. Results Overall, the Cronbach alpha for the VeLUSET-FR was 0.96 (95\% Cl 0.93 to 0.98$)$ on test and retest. Lin's concordance correlation coefficient of test and retest scores was 0.93 (95\% $\mathrm{Cl} 0.86$ to 0.96$)$.

Conclusion The results indicate that the VeLUSET-FR is a valid and reliable instrument for measuring self-efficacy among Swiss-French persons affected by a venous leg ulcer. Our findings show that the psychometric properties are similar to those of the original tool. Therefore, we suggest that the VeLUSET-FR can be effectively used for measuring self-efficacy in Swiss-French persons with VLU.

\section{INTRODUCTION}

Venous leg ulcers (VLU) are caused by chronic venous insufficiency. The prevalence can reach up to $3 \%$ in the general population in industrialised countries. ${ }^{1}$ In $60 \%$ of cases these wounds heal within three to 6 months, another $33 \%$ heal within 1 year. In $7 \%$ of cases, wound closure never occurs. ${ }^{2}$ Up to $70 \%$ of persons with leg ulcers suffer a recurrence within 3 months after wound closure. ${ }^{3-5}$ Hence, VLUs are a health problem that often accompanies a person for life. ${ }^{6}$

Consequently, these wounds are a burden not only on the affected persons as they, cause pain and suffering, they also require expensive treatment which is a burden on their personal budget, their social environment and on society as a whole. The estimated annual treatment-costs for 2.2 million persons with VLU in the United Kingdom are estimated to be in the vicinity of $£ 6$ billion. ${ }^{7}$

\section{Strengths and limitations of this study}

- The study had a high participation rate.

- The study has a high level of data-completeness.

- Reliability was examined using Bland-Altman, Pearson's correlation coefficient as well as Lin's concordance correlation coefficient with 95\% Cls.

- Generalisation is possibly limited of the Frenchspeaking population of Switzerland.

Current therapeutic approaches for VLUs are multifaceted and focus on promoting wound healing as well as the prevention of ulcer recurrences. ${ }^{8}$ This is achieved through the wearing of compression hosiery, leg and ankle exercises, elevation and a healthy and balanced diet. ${ }^{89}$ However, adherence to the therapeutic recommendations is poor. ${ }^{1011}$

As an explanation for this low level of therapeutic adherence the literature cites a lack of knowledge. ${ }^{11-13}$ As a lack of knowledge is associated with a low level of self-care and self-efficacy (the confidence in one's ability to perform a task successfully), ${ }^{14-16}$ a promising strategy to prevent VLU recurrences could be the strengthening/improvement of self-efficacy and self-care. Additionally a high level of self-efficacy was identified as a determinant for decreased hospital re-admission rates and increased quality of life. ${ }^{17}$

Currently, only one self-efficacy instrument has been developed to measure the selfefficacy of persons with VLU in their self-care activities, the VeLUSET. ${ }^{16}{ }^{17}$ It measures the self-care and-indirectly-the knowledge level of persons with leg ulcers. ${ }^{16}$ Developed and validated by Brown (2014), ${ }^{17}$ it consists of general statements about wearing the compression stocking (five items) and of affirmations about the daily self-care tasks (16 items), that the persons can agree or not with a scale from 0 (total disagreement) to 10 (total agreement). Mean scores for each 
item can be compared. Its internal reliability is $0.931 .^{17}$ There is no comparable tool in French that measures selfefficacy in persons with venous ulcers. In agreement with the original author, a translation and psychometric exploration of the VeLUSET were undertaken in a clinical context, within the French-speaking part of Switzerland.

\section{PURPOSE OF THE STUDY}

To evaluate the psychometric properties and in particular the internal consistency and reliability of the SwissFrench version of the Venous Leg Ulcer Self Efficacy Tool (VeLUSET).

\section{DESIGN}

After the forward and backward translation as described by Maneesriwongul and Dixon, ${ }^{18}$ a separate study was conducted to determine the internal consistency and reliability of the VeLUSET-FR for use in the VLU-population in the French-Speaking part of Switzerland using a testretest design.

\section{Sample size}

Calculation of the required sample size for the study was conducted using Power Analysis Sample Size (PASS) software. ${ }^{19}$ Significance level (alpha) was set at 0.05 (twotailed), items at 30 , power at 0.9 , the expected effect size at 0.3 (conservative estimate). The required sample size was 27 participants.

\section{Setting and public patient involvement}

A sample of 32 consecutive persons with VLU from three wound care centres in the French speaking part of Switzerland was recruited (centre A: 18; centre B: 13; centre C: 1). All participants met the following inclusion criteria: having a healed or recurrent ulcer, suitable for compression therapy, an ankle brachial systolic pressure index between 0.8 and 1.3 , be over 18 years of age, a return visit scheduled within 2 weeks and proficiency in French language. Trained staff nurses at the participating centres screened the daily appointment lists in order to identify potential participants. Subsequently those persons meeting the inclusion criteria were asked for consent to be referred to the study nurse for recruitment. The recruitment into the study and data collection period was from February to October 2018.

\section{The instrument}

The original version of the VeLUSET was developed to measure self-care and self-efficacy in English persons 60 years of age and older with venous ulcers. ${ }^{16}$ The tool is a 30-item self-report that assesses the four dimensions of self-efficacy for persons with VLU: general self-care (five items), daily self-care tasks (12 items), normal living (four items), developing expertise (six items) and avoiding trauma (three items). The scale was developed by focus groups made up of people who are experiencing VLU. The items were written in the form of statements based on self-efficacy findings. This formulation assesses the person's understanding of the aetiology of their ulcer and provides the latest recommendations on self-care to be adopted. The scale is presented in a Likert format between 0 (totally disagree) and 10 (totally agree). The content validity of the tool was confirmed by a panel of four experts. The VeLUSET has been reported to have good internal consistency for the total scale (Cronbach alpha $=0.931$ ) and for the subscales (Cronbach alpha $=0.834 ; 0.851 ; 0.753 ; 0.828$ and 0.804 respectively). The test-retest reliability over a 4-week interval shows a strong positive Pearson's correlation $(\mathrm{r}=0.92 ; \mathrm{n}=20$; $\mathrm{p}<0.001)$.

\section{Demographic background}

The demographic section of the questionnaire included questions about participants' age, gender, highest level of education and number of recurrences.

\section{DATA COLLECTION PROCEDURE}

Administration of the Swiss-French version of the VeLUSET

Internal consistency and reliability of the translated VeLUSET-scale was assessed in a test-retest study of 32 respondent's after a period of 14 days. A timeframe of 2 weeks between initial and repeat data collection is suggested by Sharma ${ }^{19}$ to minimise the influence of clinical changes.

\section{DATA ANALYSIS}

SPSS V. $25^{20}$ was used for data entry and analysis. Data entry was conducted by MT and audited by SP for accuracy. Summary descriptive statistics of the demographic characteristics of the study population were calculated. Cronbach alpha was calculated to assess the internal consistency of both the test and retest results of the SwissFrench version of the VeLUSET. Further assessment of reliability was conducted using Spearman's correlation coefficient between subscales and all items. As the data was non-parametric a paired Wilcoxon test was used to assess the differences between test and retest results.

A Bland and Altman plot of differences against averages of test and retest results was created. Pearson's correlation coefficient was calculated to assess the relationship between differences and averages. ${ }^{21}{ }^{22}$ Further the Lin concordance correlation coefficient between test and retest results as well as the $95 \%$ CI was calculated. ${ }^{23}$

\section{Ethical approval}

All participants received an information document and a consent form detailing the objectives of the study, the procedures involved, insurance and confidentiality of the data. All participants gave their written consent prior to data collection.

\section{RESULTS}

Participation rate

Of the 35 potential participants invited, 32 provided informed consent resulting in a participation rate of $91 \%$. 


Table 1 Demographic characteristics of study population
$n=32$

\section{Characteristic*}

\begin{tabular}{lll}
\hline Mean age (SD) & 70.8 & $(15.8)$ \\
Male & 61.8 & $(17.0)$ \\
Female & 75.5
\end{tabular}

Gender

\begin{tabular}{lrr} 
Male & 11 & 34.4 \\
\hline Female & 21 & 65.6 \\
\hline Marital status & & \\
Single & 5 & 15.6 \\
Married & 12 & 37.5 \\
Divorced & 3 & 9.4 \\
Widowed & 12 & 37.5
\end{tabular}

Highest education level

\begin{tabular}{lrc} 
Primary school & 8 & 25 \\
\hline Compulsory school & 6 & 18.8 \\
\hline Vocational training & 17 & 53.1 \\
\hline Tertiary education & 1 & 3.1 \\
\hline Professional activity & & \\
In paid employment & 6 & 18.8 \\
\hline Retired & 24 & 75 \\
\hline Disability pension & 2 & 6 \\
\hline
\end{tabular}

* Values given are either mean and SD or absolute and relative frequencies.

All participants completed the questionnaires at the time of testing and retesting with no missing data.

\section{Demographic characteristics of study population}

Of the 32 participants the majority $(65.6 \%, \mathrm{n}=21)$ was female, retired $(75 \%, \mathrm{n}=24)$, had an education level of vocational training $(53.1 \%, \mathrm{n}=17)$ and was either married or widowed $(37.5 \%$ each, $\mathrm{n}=12$ ) (table 1$)$. The mean age of all participants was 70.8 years (SD 15.8), ranging from 41 years to 96 years. The mean age of male participants with 61.8 years (SD 17.0; 95\% CI 50.4 to 73.2 ) was younger than that of female participants with 75.5 years (SD 13.2; $95 \%$ CI 69.5 to 81.5 ).

\section{Time between measurements}

The mean time between the administration of test and retest was 16.4 days (SD 4.11), with a minimum of 10 and a maximum of 27 days. The majority of participants $(80 \%)$ were retested after 12 to 21 days.

\section{Internal consistency}

Cronbach alpha for the five subscales ranged between 0.74 and 0.98 on the first measurement and 0.86 and 0.96 on the second measurement while that of the total score was 0.96 (95\% CI 0.93 to 0.98 on both occasions (table 2). The lowest subscale scores for Cronbach alpha were for 'avoiding trauma' with values of 0.74 and 0.86 at test and retest whereas the two highest subscale scores were for 'normal living' with 0.98 and 0.96 respectively. Spearman's correlation coefficients between the subscales were all significant (table 2).

\section{Reliability}

The inspection of the scatterplot of the test versus the retest scores showed that the responses on the retest were on average lower (median 230.5; IQR (209.25; 275.00); range 79-299) than on the initial test (median 237.50; IQR (196.75; 265.00); range 71-300) ( $\mathrm{p}=0.338$, two-sided).

The agreement between the single items ranged from $28.1 \%$ to $71.9 \%$. The Bland-Altman plot of the averages of test and retest scores versus the differences of the test and retest scores shows concordance between test and retest scores (figure 1). The Limits of Agreement ( -40.16 ; 48.16 ) contain 30 of the 32 measurement pairs also indicating good agreement.

Lin's concordance correlation coefficient of the test and retest scores was 0.929 with a $95 \%$ CI from 0.86 to 0.96 two-sided, Pearson's correlation coefficient for this relationship was not significant $(\mathrm{r}=0.10 ; \mathrm{p}=0.625)$ demonstrating good overall reproducibility.

Table 2 Spearman's correlation coefficients between VeLUSET-FR subscales (test) and Cronbach alpha values based on 32 answers.

\begin{tabular}{|c|c|c|c|c|c|c|c|}
\hline & \multicolumn{5}{|c|}{ Subscales of VeLUSET-FR } & \multicolumn{2}{|c|}{ Cronbach alpha } \\
\hline & $\begin{array}{l}\text { General self- } \\
\text { care }\end{array}$ & $\begin{array}{l}\text { Daily self-care } \\
\text { tasks }\end{array}$ & $\begin{array}{l}\text { Normal } \\
\text { living }\end{array}$ & $\begin{array}{l}\text { Developing } \\
\text { expertise }\end{array}$ & $\begin{array}{l}\text { Avoiding } \\
\text { trauma }\end{array}$ & Test & Retest \\
\hline Daily self-care tasks & $0.760^{\star}$ & - & & & & 0.900 & 0.860 \\
\hline Normal living & $0.603^{*}$ & $0.658^{\star}$ & - & & & 0.979 & 0.956 \\
\hline Total & & & & & & 0.964 & 0.957 \\
\hline
\end{tabular}

* Significant at 0.01 level, two-sided. 


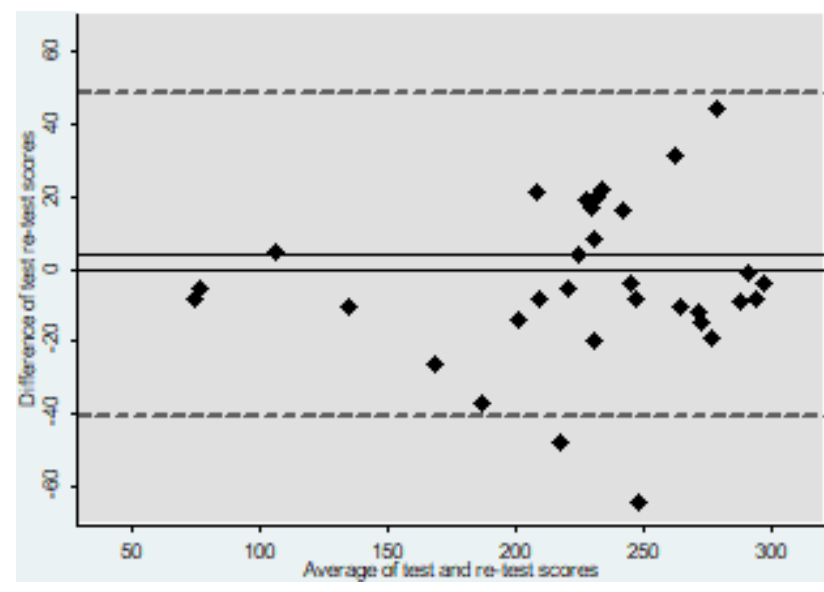

Figure 1 Bland-Altman plot for 32 participants.

\section{DISCUSSION}

This study was conducted to determine the psychometric properties of the VeLUSET-FR. A response rate of $91 \%$ was achieved in this study. The questionnaire was easily understandable and was well accepted as demonstrated by the high participation rate and the high level of data-completeness (no missings). The mean age of participants in our study was 71 years compared with the one of the original study (74 years) which is comparable. ${ }^{17}$ The VeLUSET-FR also demonstrated an acceptable internal consistency with a total score of 0.96. Again this is a similar Cronbach alpha value like the one reported by Brown et al which was 0.93 .

This study's findings on reliability demonstrate that the responses on the retest were on average lower (median 230.5; IQR (209.25; 275.00); range 79-299) than on the initial test (median 237.50; IQR (196.75; 265.00); range 71-300) ( $\mathrm{p}=0.338$, two-sided) which is expected and compares to the validation study conducted by Brown.

In addition to Brown's validation study on the VeLUSET instrument we expanded the examination of the psychometric properties by producing a Bland-Altman plot as well as Lin's concordance between test and retest as a demonstration of the reliability of the instrument. The results indicate an overall good reproducibility of 0.929 with a $95 \%$ CI from 0.86 to 0.96 two-sided although the Pearson's correlation coefficient for this relationship was not significant $(r=0.10 ; p=0.625)$.

A possible limitation of the study is a restriction of the generalisation of the findings to the French speaking population in Switzerland as well as a relatively small sample size.

\section{CONCLUSION}

The psychometric properties of the Swiss French version of the VeLUSET are based on good quality data. Validity and reliability are adequate and comparable to the psychometric properties of the original instrument. Therefore we recommended the VeLUSET-FR for the measurement of self-care in the Swiss French venous leg ulcer population.

Contributors All authors were responsible and accountable to all part of works related to the study. More specifically, SP had the original idea. SP and MBS contributed to the conception and design of the study and acquired the funding. SP and MT collected data and MBS and SP analysed and interpreted the data. SP, MT and MBS contributed in writing the manuscript. All authors revised the manuscript and gave the approval to the final version to be published.

Funding This study was funded with an unrestricted grant of the Ebnet foundation, Switzerland.

Competing interests None declared.

Patient consent for publication Obtained.

Ethics approval The ethical committee of the canton of Geneva granted this study (2017-0516).

Provenance and peer review Not commissioned; externally peer reviewed. Data availability statement Data are available upon reasonable request.

Open access This is an open access article distributed in accordance with the Creative Commons Attribution Non Commercial (CC BY-NC 4.0) license, which permits others to distribute, remix, adapt, build upon this work non-commercially, and license their derivative works on different terms, provided the original work is properly cited, appropriate credit is given, any changes made indicated, and the use is non-commercial. See: http://creativecommons.org/licenses/by-nc/4.0/.

ORCID iD

Sebastian Probst http://orcid.org/0000-0001-9603-1570

\section{REFERENCES}

1 Norman G, Westby MJ, Rithalia AD, et al. Dressings and topical agents for treating venous leg ulcers. Cochrane Database Syst Rev 2018;10.

2 Harrisson MB, Graham ID, Friedberg E, et al. Assessing the population with leg and foot ulcers. Canadian Nurse 2001;97:18-23.

3 Abbade LPF, Lastória S, de Almeida Rollo H, et al. A sociodemographic, clinical study of patients with venous ulcer. Int $J$ Dermatol 2005;44:989-92.

4 McDaniel HB, Marston WA, Farber MA, et al. Recurrence of chronic venous ulcers on the basis of clinical, etiologic, anatomic, and pathophysiologic criteria and air plethysmography. J Vasc Surg 2002;35:723-8.

5 Finlayson K, Wu M-L, Edwards HE. Identifying risk factors and protective factors for venous leg ulcer recurrence using a theoretical approach: a longitudinal study. Int J Nurs Stud 2015;52:1042-51.

6 Saha SP, Whayne TF, Mukherjee DP. Current management of peripheral vascular disease: where is the evidence? Cardiovasc Hematol Agents Med Chem 2011;9:128-36.

7 Guest JF, Ayoub N, Mcllwraith T, et al. Health economic burden that wounds impose on the National health service in the UK. BMJ Open 2015;5:e009283.

8 Probst S, Allet L, Depeyre J, et al. A targeted interprofessional educational intervention to address therapeutic adherence of venous leg ulcer persons (TIEIVLU): study protocol for a randomized controlled trial. Trials 2019;20:243.

9 Barber GA, Weller CD, Gibson SJ. Effects and associations of nutrition in patients with venous leg ulcers: a systematic review. $J$ Adv Nurs 2018;74:774-87.

10 Franks PJ, Barker J, Collier M, et al. Management of patients with venous leg ulcers: challenges and current best practice. J Wound Care 2016;25:S1-67.

11 Health Quality O. Compression stockings for the prevention of venous leg ulcer recurrence: a health technology assessment. Ont Health Technol Assess Ser 2019;19:1-86.

12 Edwards LM, Moffatt CJ, Franks PJ. An exploration of patients' understanding of leg ulceration. J Wound Care 2002;11:35-9.

13 Finlayson K, Edwards H, Courtney M. The impact of psychosocial factors on adherence to compression therapy to prevent recurrence of venous leg ulcers. J Clin Nurs 2010;19:1289-97.

14 Van Hecke A, Grypdonck M, Beele H, et al. Adherence to leg ulcer lifestyle advice: qualitative and quantitative outcomes associated with a nurse-led intervention. J Clin Nurs 2011;20:429-43.

15 González A. Education project to improve venous stasis selfmanagement knowledge. J Wound, Ostomy and Continence Nursing 2014;41:556-9.

16 Brown A. Evaluating the reasons underlying treatment nonadherence in VLU patients: Mishel's theory of uncertainty. Part 2 of 2. J Wound Care 2014;23:73-80.

17 Brown A, Kendall S, Flanagan M, et al. Encouraging patients to selfcare - the preliminary development and validation of the VeLUSETC, a self-efficacy tool for venous leg ulcer patients, aged 60 years and over. Int Wound J 2014;11:326-34.

18 Maneesriwongul W, Dixon JK. Instrument translation process: a methods review. J Adv Nurs 2004;48:175-86.

19 Hintze J. PASS 12. Kaysville, Utah, USA: NCSS, LLC, 2013. 
20 Sharma M. Making sense of factor analysis. The use of factor analysis for instrument development in health care research. $J$ Alcohol Drug Educ 2016;60:84-6.

21 IBM Corp. Ibm SPSS statistics for windows, 25.0 ed. Armonk, NY, 2017.
22 Bland JM, Altman DG. Statistical methods for assessing agreement between two methods of clinical measurement. Lancet 1986;1:307-10.

$23 \mathrm{Lin} \mathrm{LI.} \mathrm{A} \mathrm{concordance} \mathrm{correlation} \mathrm{coefficient} \mathrm{to} \mathrm{evaluate}$ reproducibility. Biometrics 1989;45:255-68. 